\title{
MECANISMOS DE INTERAÇÃO E TRANSPORTE DO METAL CHUMBO EM DIFERENTES COMPOSIÇÕES DE
} SOLOS

\author{
Adan William da Silva Trentin ${ }^{1}$, Adeli Beatriz Braun ${ }^{1}{ }^{*}$, Caroline Visentin ${ }^{1}$, Julia Favretto ${ }^{1}$, Antônio Thomé ${ }^{1}$ \\ 1 Programa de Pós-Graduação em Engenharia Civil e Ambiental, Universidade de Passo Fundo, 99052-900, Passo Fundo, Brasil.
}

*E-mail: adelibeatrizbraun@ hotmail.com

\section{RESUMO}

O chumbo, devido principalmente à sua alta toxicidade e nocividade à saúde humana e aos ecossistemas naturais, é um metal tóxico prejudicial em qualquer concentração para os organismos vivos. Diante disto, este trabalho objetivou verificar o comportamento, interação, mobilidade e transporte do metal chumbo nos mais diversos tipos e composições de solos. Para alcançar tal objetivo realizouse uma caracterização do metal chumbo, discorrendo sobre suas principais propriedades físico-químicas, um estudo referente às propriedades geoquímicas dos solos, além da identificação dos parâmetros de transporte os quais influenciam diretamente na interação e transporte do contaminante no solo. Os resultados indicaram que a capacidade adsortiva é o processo mais evidenciado nas interações entre o solo e o chumbo. Em relação ao transporte, este é influenciado fundamentalmente por fatores como o fluxo de fluido no qual os contaminantes estão dissolvidos, além das características do contaminante, do solo e as condições ambientais. Portanto, conclui-se que as propriedades físico-químicas específicas do metal chumbo, em conjunto com as características e composições mineralógicas de cada solo que o mesmo interage, são parâmetros que orientam o seu comportamento no solo, quanto a sua disponibilidade, mobilidade e possibilidade de remoção.

Palavras-chave: Poluição do solo. Metais tóxicos. Interação solo-contaminante. Parâmetros de mobilidade.

\section{Introdução}

O solo é um recurso natural essencial para a sustentação da vida na terra. No entanto, com o crescimento populacional aliado ao consumo desenfreado de produtos e as atividades antrópicas, juntamente com a intensificação dos processos industriais, resultaram em inúmeros locais contaminados pelo mundo, acentuando os crescentes problemas da poluição dos solos e da água. Problemas estes oriundos principalmente devido à introdução dos mais diversos contaminantes no ambiente, representando uma enorme ameaça para a saúde humana e o ecossistema natural [1-2].

Dentre os diversos contaminantes possíveis de serem introduzidos no solo, os metais tóxicos merecem destaque em função de seu comportamento ambiental e toxicológico extremamente diferenciado e específico, comparado aos outros poluentes, por sua perenidade no ambiente, ação acumulativa e por serem absolutamente não degradáveis. Estes tipos de metais, tais como: sódio, potássio, bário, cálcio, ferro, zinco, cobre, níquel, magnésio, arsênio, chumbo, cádmio, mercúrio, alumínio, titânio, estanho, tungstênio, cromo, cobalto e manganês, são elementos químicos com uma densidade atômica maior do que 6 g. $\mathrm{cm}^{-3}$ e de peso atômico elevado, que em concentrações elevadas se apresentam muito tóxicos à saúde humana e aos ecossistemas naturais [3-5].

Os metais tóxicos são altamente reativos e apresentam-se, muitas vezes, associados a outros elementos químicos. Estes tipos de metais não se concentram somente no solo, seguem diferentes vias de contaminação, podendo alcançar, em função de sua mobilidade, as águas superficiais e subterrâneas. Nos solos, os metais tóxicos são adsorvidos, complexados ou precipitados, podendo co-precipitar com outros elementos ou transformar-se em outros contaminantes. No caso da adsorção destes metais tóxicos pelo solo, mais especificamente, parte destes metais poderá ser absorvido pelas plantas e até mesmo volatilizar e ser liberado para o ar [6-7].

A presença de metais tóxicos no ambiente ocorre desde a formação do planeta, nunca se esgotam e devem sempre existir, podendo ser encontrados em todos os lugares. Portanto, podem ser encontrados naturalmente nos solos sem qualquer interferência humana, porém, é a influência antropogênica a responsável pelos grandes danos ambientais associados a estas substâncias. As principais fontes de disseminação da contaminação por metais tóxicos concentram-se na aplicação de defensivos agrícolas ou de fertilizantes, despejo de resíduos sólidos e industriais, lançamento 
de esgotos domésticos, postos de combustíveis e resíduos resultantes do processo petroquímico e das indústrias metalúrgicas e mineração $[4,5,8,9]$.

Diante disto, alguns metais tóxicos estão presentes em concentrações muito pequenas na maioria dos organismos vivos, tornando-se tóxicos para a saúde humana quando ultrapassam determinadas concentrações-limite. Numerosos estudos relataram o efeito adverso dos metais nas propriedades do solo, no crescimento das plantas, na qualidade dos alimentos e na qualidade da água [10-15]. Já o chumbo não existe naturalmente em nenhum organismo, nem desempenha funções nutricionais ou bioquímicas em microorganismos, plantas ou animais, sendo sua presença em organismos vivos prejudicial em qualquer concentração [3].

No ambiente o chumbo está presente naturalmente em concentrações muito baixas, sendo encontrado em rochas sedimentares, como carbonatos puros (cerca de $5 \mathrm{ppm}$ ), arenitos (cerca de $10 \mathrm{ppm}$ ) e folhetos negros (cerca de $23 \mathrm{ppm}$ ) [16]. No entanto, são as fontes antrópicas de inserção deste metal no meio ambiente que merecem destaque, as quais estão relacionadas com as atividades de mineração e de fundição, indústria do ferro e do aço, refinarias, sucatas, aterros, esgotos, pesticidas, fabricação de baterias, tintas e automóveis, o que resulta em uma produção anual de chumbo e seus derivados na ordem de milhões de toneladas [16].

O solo possui grande capacidade de retenção do chumbo, imobilizando o mesmo principalmente por meio da adsorção. Porém, essa imobilização é temporária, pois quando as condições ambientais mudam, as reações químicas são alteradas e o contaminante torna-se móvel e perigoso novamente, criando condições que facilitam a lixiviação, podendo comprometer a qualidade dos sistemas aquáticos adjacentes e das águas do lençol freático [17].

Desta forma, o chumbo apresenta algumas características fundamentais, como a condutividade elétrica, resistência, solubilidade, reatividade, disponibilidade, afinidade e mobilidade, as quais orientam o seu comportamento no solo. De uma forma geral, a disponibilidade dos mais diferentes contaminantes, inclusive os metais tóxicos como o chumbo, depende muito das suas características, especiações e toxicidade. No entanto, a influência mais significativa desta relação de disponibilidade em diferentes solos depende em sua maioria dos minerais presentes e de suas propriedades específicas [18-20].

Para a previsão dos impactos de uma área sujeita à contaminação, faz-se necessário o conhecimento dos mecanismos e parâmetros de transporte dos contaminantes envolvidos. Sua migração em meios porosos é governada por diversos processos. Os processos físicos envolvem os fenômenos da advecção e dispersão hidrodinâmica, enquanto os processos químicos englobam as diversas reações químicas que podem ocorrer entre a solução contaminada e o solo [21].

Desta forma, este trabalho tem como objetivo realizar uma revisão bibliográfica sistemática a fim de verificar $o$ comportamento, interação, mobilidade e transporte do metal chumbo nos mais diversos tipos e composições de solos. Para tanto, realizou-se uma caracterização do metal chumbo, discorrendo sobre suas principais propriedades físico-químicas, um estudo referente às propriedades geoquímicas dos solos, além da identificação dos parâmetros de transporte os quais influenciam diretamente na interação e transporte do contaminante no solo.

\section{Chumbo}

$\mathrm{O}$ chumbo $(\mathrm{Pb})$ encontra-se em primeiro lugar no ranking dos contaminantes mais comuns em solos, ficando à frente do $\mathrm{Cr}$, $\mathrm{As}, \mathrm{Zn}, \mathrm{Cd}, \mathrm{Cu}$ e Hg. Além disto, é encontrado na segunda posição da lista prioritária das substâncias perigosas adotada pela Organização Mundial de Saúde (OMS) [16,22].

A contaminação dos solos por este metal ocorre devido principalmente à sua baixa mobilidade no perfil do solo e a elevada adsorção na fase sólida, fazendo com que o chumbo se acumule principalmente nos primeiros centímetros de solo, geralmente na forma de chumbo elementar, óxidos e hidróxidos de chumbo, e complexos metal-chumbo [23].

Esta contaminação pode vir a causar graves problemas ambientais, porém, os efeitos nocivos à saúde humana são os mais preocupantes, e a magnitude destes efeitos depende da dose e do tempo de exposição ao contaminante. $\mathrm{O}$ chumbo é normalmente introduzido no organismo através da inalação e ingestão e se acumula nos tecidos ricos em cálcio tais como ossos, fígado e rins, causando uma doença denominada saturnismo ou plumbismo. Os efeitos, em função principalmente do seu caráter bioacumulativo, incluem principalmente anemia, disfunções neurológicas e renais, podendo ser carcinogênico, teratogênico (anomalias genéticas) e causar abortos e infertilidade [24].

Desta forma, segundo Machado [24] o chumbo é um metal tóxico que é prejudicial aos microrganismos vivos em qualquer concentração e a sua toxicidade elevada está relacionada às formas iônicas $\left(\mathrm{Pb}^{2+}\right.$ e $\left.\mathrm{Pb}^{4+}\right)$ e ao chumbo orgânico tetravalente, o qual realiza ligações de caráter covalente.

A remediação do chumbo do solo pode ser realizada através de técnicas de mobilização, imobilização, contenção, separação ou remoção. Estas técnicas podem ser divididas em processos biológicos, térmicos e físico-químicos [5,25].

Dentre os principais métodos conhecidos, conforme Tran e colaboradores [26], a adsorção possui grande potencial para a 
remoção de chumbo, apresentando-se um método eficaz, econômico e simples, sendo que a maior vantagem está relacionada com a sua aplicabilidade em concentrações muito baixas de contaminante. Dentre os vários meios adsorventes que podem ser utilizados, os argilominerais apresentam características importantes, como os sítios ativos na superfície das partículas, para atuarem como bons adsorventes de metais tóxicos inclusive o chumbo.

No Brasil, visando o controle da qualidade da água subterrânea e dos solos, em função da contaminação por diferentes tipos de contaminantes, têm-se a Resolução $n^{\circ} 420$ de dezembro de 2009 emitida pelo Conselho Nacional de Meio Ambiente (CONAMA), a qual traz os valores orientadores do chumbo para o solo. $\mathrm{O}$ valor de prevenção no qual o solo possui capacidade de sustentar as suas funções principais é de $72 \mathrm{mg} \cdot \mathrm{kg}^{-1}$ e o valor de investigação para solos agrícolas é de $180 \mathrm{mg} \cdot \mathrm{kg}^{-1}$, sendo que, os valores de referência são definidos por cada Estado, no caso do Rio Grande do Sul pela Portaria da Fundação Estadual de Proteção Ambiental (FEPAM), nº 85 de 2014.

\subsection{Propriedades físicas e químicas}

O chumbo é um metal pesado de coloração cinza-azulada, altamente maleável, baixa condutividade elétrica e temperatura de fusão (Tabela 1) e muito resiste à corrosão. É um elemento químico o qual apresenta como símbolo $\mathrm{Pb}$ e na tabela periódica pertence ao grupo 14 (IV A), o grupo do carbono, com número atômico 82 e massa molecular de $207,2 \mathrm{~g} \mathrm{~mol}^{-1}$. Encontra-se no sexto período e corresponde a um metal representativo. Além disto, o chumbo natural é uma mistura de quatro isótopos estáveis, ${ }^{204} \mathrm{~Pb}(1,35-1,5 \%),{ }^{206} \mathrm{~Pb}(23.5-27 \%),{ }^{207} \mathrm{~Pb}(20,5-23 \%)$ e ${ }^{208} \mathrm{~Pb}(51-$ $53 \%$ ), sendo que, as proporções de isótopos variam para os diferentes minerais [18,27-29].

Tabela 1. Principais propriedades do metal chumbo

\begin{tabular}{cc}
\hline \multicolumn{2}{c}{ Propriedades } \\
\hline Estado da matéria & Sólido \\
Densidade & $11,34 \mathrm{~g} \mathrm{~cm}^{-3}$ a $20^{\circ} \mathrm{C}$ \\
Condutividade elétrica & $4,81 \times 10^{6} \mathrm{~m}^{-} 1 . \Omega^{-1}$ \\
Condutividade térmica & $35,3 \mathrm{~W} \cdot(\mathrm{m} \cdot \mathrm{K})^{-1}$ \\
Ponto de fusão & $327,4{ }^{\circ} \mathrm{C}$ \\
Temperatura de vaporização & $1.725^{\circ} \mathrm{C}$ \\
Estados de oxidação & $2 \mathrm{e} 4$ \\
Raio iônico & $0,132 \mathrm{~nm}(2)$ e $0,084 \mathrm{~nm}(4)$ \\
Raio de van-der-waals & $0,154 \mathrm{~nm}$ \\
Eletronegatividade & $2,33($ Escala de Pauling)
\end{tabular}

Fonte: Elaborada pelos Autores com base em ICZ [29].
O chumbo se apresenta muito resistente à oxidação atmosférica e ao ataque dos ácidos clorídrico ou sulfúrico diluídos, sendo que, no caso de ácido sulfúrico concentrado e quente transforma-o em sulfato de chumbo $\left(\mathrm{PbSO}_{4}\right)$, mas é rapidamente dissolvido pelo ácido nítrico (a temperatura normal, originando nitrato de chumbo $\left(\mathrm{Pb}\left(\mathrm{NO}_{3}\right)_{2}\right)$. Apresenta, portanto, solubilidade em ácido sulfúrico concentrado e quente e no ácido nítrico, mas insolúvel em água e em solventes orgânicos. Da mesma forma, possui grande afinidade com íons inorgânicos contendo oxigênio (por exemplo, carbonato) ou enxofre, podendo formar diversos minerais sulfetados, sendo o seu mineral mais comum, um sulfeto, denominado galena $(\mathrm{PbS})$ [18,27-29].

No solo o chumbo pode estar sob diversas formas, relativamente insolúvel, solúvel, coprecipitado, adsorvido em matérias orgânicas coloidais e/ou complexado no solo. Além disto, o pH do solo influencia na mobilidade do metal no solo, que pode sofrer modificações, formar compostos menos solúveis e tornar-se menos disponível. Em pHs elevados a tendência é a formação de fosfatos e carbonatos insolúveis, ao passo que em $\mathrm{pHs}$ baixos tendem a ser encontradas espécies iônicas livres, solúveis e mais disponíveis [18].

A abundância média de chumbo na crosta terrestre é estimada em cerca de $15 \mathrm{ppm}$. O conteúdo natural de chumbo no solo está, é claro, relacionado à composição da rocha mãe. Embora as espécies de chumbo variem consideravelmente com o tipo de solo, elas estão associadas principalmente a argilominerais, óxidos de $\mathrm{Mn}$, hidróxidos de $\mathrm{Fe}$ e $\mathrm{Al}$ e matéria orgânica. Em alguns tipos de solo, o chumbo pode ser altamente concentrado em partículas de carbonato de $\mathrm{Ca}$ ou em concentrações de fosfato. Um valor basal de chumbo para o solo de superfície na escala global foi estimado em $25 \mathrm{mg} \cdot \mathrm{kg}^{-1}$; níveis acima sugerem uma influência antrópica [30-31].

Em relação à estabilidade, $\mathrm{o} \mathrm{Pb}^{2+}$ é a forma mais estável dos íons, porém, para cada faixa de $\mathrm{pH}$ são encontradas espécies estáveis variáveis. Para a faixa de $\mathrm{pH}$ entre 0 e 7 são encontrados os íons plumbosos solubilizados $\left(\mathrm{Pb}^{2+}\right)$; entre 7 e 12 tem-se o óxido plumboso $(\mathrm{PbO})$ bem como o chumbo $(\mathrm{Pb})$ e o ortoplumbato de chumbo (Pb3O4); e para pH's acima de 12 são encontrados o ortoplumbato de chumbo $\left(\mathrm{Pb}_{3} \mathrm{O}_{4}\right)$ e o chumbo $(\mathrm{Pb})$. O chumbo metálico é estável na presença de soluções neutras ou alcalinas, em soluções ácidas e sob pressão atmosférica tem tendência em decompor a água e formar hidrogênio [32].

O transporte no interior do solo e a disponibilidade do chumbo no solo estão intimamente ligados ao pH, composição mineral do solo e quantidade e o tipo de material orgânico, em função principalmente da maioria do chumbo estar vinculado dentro da faixa superior do solo, entre os $5 \mathrm{~cm}$. Estes fatores 
limitam a quantidade de chumbo que pode ser libertado/lixiviado para a água ou a disponibilidade para a absorção pelas plantas [18].

\section{Solo e suas composições geoquímicas}

O solo corresponde um meio essencial de proteção das águas superficiais e subterrâneas, uma vez que age como filtro natural, tampão e meio de adsorção, degradação e transformação de substâncias químicas [33].

O solo é composto por elementos minerais (45\%), ar (25\%), água (25\%) e matéria orgânica (5\%), sendo que, a proporção de cada componente no solo pode variar de um solo para outro. A caracterização de um solo também depende da textura e da estrutura do mesmo, sendo que, é por meio de análise granulométrica do diâmetro da partícula que é possível definir se o solo é argiloso (inferior a $2 \mu \mathrm{m}$ ), siltoso (entre 2 e $5 \mu \mathrm{m}$ ), arenoso (entre $5 \mu \mathrm{m}$ e $2 \mathrm{~mm}$ ), cascalho (entre 2 e $20 \mathrm{~mm}$ ) e pedregulho (superior a $20 \mathrm{~mm}$ ) [34-35].

De acordo com Lewis [36], a química do solo é governada principalmente pela fração de coloides no solo. Essa fração consiste em minerais de argila, óxidos metálicos e partículas orgânicas. A grande área superficial dos solos coloidais fornece locais onde as moléculas na solução do solo podem se ligar através das forças atrativas de Van der Waals. Solos coloidais também possuem cargas eletrostáticas de superfície, que possibilitam a adsorção, ligações químicas e troca de íons e moléculas na superfície das partículas. As cargas eletrostáticas de superfície têm origem da substituição isomórfica, ionização de grupos funcionais ou adsorção específica, dependendo da natureza da partícula.

Os minerais do solo são divididos em minerais primários e secundários. Os minerais primários são os chamados silicatos, os quais são classificados com base na estrutura tetraédrica e ligação de sílica $\left(\mathrm{SiO}_{4}\right)$, sendo piroxênios, anfibólios e micas alguns exemplos de minerais de silicato. Os minerais secundários são produtos de minerais primários, apresentando tipicamente um tamanho de partículas menor que $2 \mu \mathrm{m}$ e, portanto, pertence por definição a fração de argila do solo [37].

Os minerais de argila são geralmente carregados negativamente, o que corresponde um fator muito importante que influencia as propriedades de sorção do solo, e a sua participação em muitas reações químicas importantes do solo, além de ser composta de várias combinações de folhas tetraédricas e octaédricas empilhadas, dando origem à argilominerais do tipo 1:1 e $2: 1$ [37-38].

A ligação de uma camada tetraédrica com uma octaédrica define um mineral de argila 1:1, tendo como exemplo a caulinita e haloisita. Os minerais se unem através de ligações de hidrogênio, de forma que a água ou outros íons não consigam entrar nas camadas. Esse tipo de argilomineral é considerado não-expansivo. Cátions monovalentes podem ser adsorvidos entre as camadas, porém a Capacidade de Troca Catiônica (CTC) desse tipo de mineral é baixa, devido à baixa substituição isomórfica. Argilas com duas camadas tetraedrais separadas por uma camada octaedral, na forma de um sanduíche, definem os minerais de argila 2:1, como é o caso da montmorilonita. As camadas de montmorilonita são mantidas unidas por moléculas de água e podem se expandir para se unir com mais moléculas de água e íons hidratados. Esses argilominerais apresentam maior área superficial e maior CTC, aumentando a capacidade de imobilização e retenção de íons metálicos [36].

São vários os minerais de argila que podem ser destacados e diferenciados, devido a sua estrutura (1:1 e 2:1), vínculo da camada, CTC, e área superficial, como por exemplo, haloisita, caulinita, esmectita, vermiculita, ilita e clorita (Tabela 2).

Tabela 2. Argilominerais mais comuns e suas características

\begin{tabular}{|c|c|c|c|c|}
\hline $\begin{array}{c}\text { Minerais de } \\
\text { Argila }\end{array}$ & Estrutura & $\begin{array}{c}\text { Vínculo } \\
\text { da } \\
\text { camada }\end{array}$ & $\begin{array}{c}\text { Capacidade } \\
\text { de Troca } \\
\text { Catiônica } \\
(\text { CTC }) \\
\left(\mathrm{Cmol}_{\mathrm{ckg}}{ }^{-1}\right)\end{array}$ & $\begin{array}{c}\text { Área } \\
\text { superficial } \\
\left(\mathbf{m}^{2} \mathbf{g}^{-1}\right)\end{array}$ \\
\hline Haloisita & $1: 1$ & $\begin{array}{l}\text { Pontes de } \\
\text { hidrogênio }\end{array}$ & $2-10$ & $78-112$ \\
\hline Caulinita & $1: 1$ & $\begin{array}{l}\text { Pontes de } \\
\text { hidrogênio }\end{array}$ & $2-5$ & $10-30$ \\
\hline Esmectita & $2: 1$ & Iônica & $80-120$ & $550-700$ \\
\hline Vermiculita & $2: 1$ & Iônica & $100-180$ & $600-800$ \\
\hline Ilita & $2: 1$ & Iônica & $20-50$ & $70-120$ \\
\hline Clorita & $2: 1: 1$ & $\begin{array}{l}\text { Pontes de } \\
\text { hidrogênio }\end{array}$ & $10-40$ & $70-100$ \\
\hline
\end{tabular}

Fonte: Elaborada pelos Autores com base em Takahashi [19] e Gustafsson [20].

O mineral de argila caulinita é mais resistente, apresentando estrutura 1:1 o que significa que ele é construído por uma folha tetraédrica e uma folha octaédrica, unidas por pontes de hidrogênio entre as camadas. A CTC é baixa devido muito a baixa substituição isomórfica, a qual corresponde a capacidade de substituir um íon estrutural por outro de carga igual ou diferente, sem alterar fundamentalmente a estrutura. A haloisita é um mineral de argila similar à caulinita, com estrutura do tipo 1: 1 também, mas com a diferença de que existem moléculas de água entre as camadas [19-20].

Os outros minerais como esmectita, vermiculita, ilita e clorita possuem a estrutura do tipo 2:1 com duas folhas tetraédricas e uma única folha octaédrica entre as duas, apresentando maior CTC e área superficial, o que proporciona maior propensão para a imobilização e retenção de íons metálicos. Já a estrutura 2:1:1 do 
mineral clorita corresponde a uma intercamada composta por uma folha octaédrica extra [19-20].

A CTC, além de depender do teor de argila presente no solo, especialmente minerais do tipo $2: 1$, ela também é condicionada pela quantidade de matéria orgânica que o solo apresenta, sendo que, a matéria orgânica quando em interação com metais tóxicos pode formar complexos e assim desempenhar um papel importante na retenção destes contaminantes no solo. Assim, quanto maior a quantidade de matéria orgânica, maior será a CTC e consequentemente mais metais tóxicos poderão ser retidos no solo [39].

Além dos minerais filossilicatos apresentados anteriormente, a argila pode também apresentar minerais de não silicato e não cristalinos, os quais apresentam estruturas mais simples. Como exemplos de não silicatos têm-se os óxidos e hidróxidos tais como goethita, gibbsita e magnetita e de minerais não cristalinos, o alofano e imogolita [20,37]. Também, além da importância das composições minerais do solo, a matéria orgânica presente no solo também desempenha papel fundamental quanto a formação de complexos com íons metálicos e a sua capacidade de retenção e imobilização destes contaminantes no solo.

A mineralogia e as propriedades de solos de regiões temperadas são diferentes de solos tropicais. As principais características que os distinguem estão relacionadas com a estrutura e a porcentagem de teor de argila presente. Solos formados em climas tropicais úmidos há a predominância de minerais de argila com estrutura $1: 1$ e quase que a ausência de estruturas 2:1. Além disto, a porcentagem de argila em solos tropicais também tende a ser mais elevada do que em solos de clima temperado [40].

No que tange a caracterização, identificação e classificação mineral, vários métodos são utilizados, dentre estes a microscopia eletrônica, que é um grupo de instrumentos com capacidade de ampliação de até 2 milhões de vezes, sendo que, o mais comumente utilizado é o Microscópio Eletrônico de Varredura (MEV), o qual fornece uma boa indicação se o material é cristalino ou amorfo. Além destes, são bastante utilizadas as técnicas de difração de raiosX para identificar estruturas cristalinas desconhecidas [41].

\section{Transporte de contaminantes}

O processo de transporte em solos porosos pode ser definido como sendo o movimento de determinado composto solução contaminante, por exemplo - em meio a uma ou mais camadas de solo, ou, em ambiente saturado ou não. Esses fenômenos vêm sendo estudados há vários anos, começando com a determinação dos fatores que promovem o transporte de compostos através do solo, até a discussão dos diferentes processos envolvidos neste transporte na década de 70 [42-43]. Já os estudos atuais concentram-se fundamentalmente no transporte de contaminantes em meios fraturados, em meios não saturados e fluxo em sistemas multifásicos [44].

O transporte de contaminantes no subsolo pode ocorrer em fase líquida, sólida ou gasosa, bem como em meio saturado, parcialmente saturado ou não saturado. A migração dos contaminantes é influenciada fundamentalmente por fatores como o fluxo de fluido no qual os contaminantes estão dissolvidos, processos físicos, químico e biológicos aos quais estas substâncias estão submetidas, além das características do contaminante, do solo e as condições ambientais, os quais determinam uma maior, menor ou nenhuma movimentação da solução contaminante nos solos [45].

Dentre as principais características do contaminante que influenciam o seu transporte nos solos estão a densidade, concentração, polaridade, solubilidade, co-solvência, volatilidade, pressão de vapor, $\mathrm{pH}$, potencial iônico, demanda biológica de oxigênio (DBO), demanda química de oxigênio (DQO), teor e finura de sólidos em suspensão, a persistência e a toxidez. A toxidez do contaminante, por exemplo, pode alterar os processos bioquímicos do solo e a sua interação com ele. Já as características básicas do solo que atuam sobre o movimento de contaminantes consistem, principalmente, no teor e tipo de matéria orgânica presente, distribuição granulométrica, mineralogia e teor de finos, distribuição de vazios, CTC e grau de saturação. Por fim, as variáveis ambientais que possuem importância para estes fenômenos são as condições climáticas, hidrogeológicas, aeróbias e anaeróbias, microorganismos nativos, temperatura, fator tempo, pressão atmosférica e o potencial redox (De Campos, 2001 apud [45]).

Os mecanismos associados à migração, retardamento ou aceleração e degradação ou decaimento estão associados com os processos físicos e bio-físico-químicos aos quais os contaminantes estão submetidos durante o fenômeno de transporte. $\mathrm{O}$ transporte de contaminantes por meio da advecção ocorre devido ao fluxo de água no solo, sendo que, os elementos dissolvidos em solução movimentam-se juntamente com o deslocamento da água com uma velocidade igual à velocidade média da água sem alterar sua concentração. Já a dispersão hidrodinâmica, que é a soma dos processos de transporte de difusão e dispersão é percebida quando os íons e moléculas dissolvidos na água se distanciam e mudam as direções das trajetórias e velocidades previstas no processo advectivo. Isso ocorre em função de que a dispersão provoca mudanças de concentração do contaminante [46-47].

A precipitação ocorre quando as novas substâncias formadas pela reação de espécies iônicas estiverem em 
concentrações superiores ao seu limite de solubilidade, sendo que, os metais tóxicos, em pHs altos tendem a reagir com carbonatos, formando compostos de baixa solubilidade, que se precipitam, diminuindo assim a mobilidade dos contaminantes. Já a dissolução, ao contrário da precipitação, disponibiliza os contaminantes em solução, sendo que, valores baixos de $\mathrm{pH}$ aumentam a taxa de dissolução e, portanto, a concentração iônica, favorecendo o transporte de contaminantes. Neste sentido, a cosolvência consiste na dissolução de uma substância em mais de um solvente podendo provocar o aumento da mobilidade de substâncias em comparação quando o solvente é a água pura [4849].

As reações de oxi-redução são aquelas que envolvem a transferência de elétrons e são importantes por controlarem a precipitação de metais. A reação que resulta na perda de elétrons é chamada de oxidação e o ganho de elétrons de redução. Já a hidrólise é a reação que ocorre com as moléculas de água, quando há a troca de um grupo aniônico da substância por uma hidroxila (OH-), resultando na decomposição desta substância [43].

Além da sorção que corresponde ao processo com maior influência na retenção de contaminantes em solos, outros fatores como o pH, a força iônica e catiônica, os ácidos orgânicos, o potencial redox e a temperatura também possuem grande importância nesse fenômeno. Um aumento do $\mathrm{pH}$ reduz a carga positiva dos hidróxidos e mobiliza formas iônicas, bem como, reduz a solubilidade de substâncias como os metais tóxicos. Além disto, uma baixa força iônica, como no caso das águas da chuva pode fazer com que ocorram fluxos preferenciais no solo, quando um grande volume de água percola por uma pequena porção de solos sem que haja um equilíbrio com o solo em solução. E também, um aumento da temperatura pode aumentar os processos ativos do solo, como por exemplo a adsorção e dessorção, o movimento de íons, a dissolução e até mesmo a precipitação [50].

No que tange o transporte de contaminantes em solos, os principais parâmetros envolvidos são a velocidade de percolação $(\mathrm{Vp})$, a condutividade hidráulica $(\mathrm{K})$, o coeficiente de dispersão hidrodinâmica (Dh), o fator de retardamento $(\mathrm{R})$ e o coeficiente de distribuição $(\mathrm{Kd})$, sendo que suas principais funções estão descritas no Quadro 1 [51-52].
Quadro 1. Principais parâmetros do transporte de contaminantes no solo.

\begin{tabular}{|c|l|}
\hline Parâmetros & \multicolumn{1}{|c|}{ Definição/Função } \\
\hline Vp & $\begin{array}{l}\text { Velocidade com que o fluido percola pelos poros, sendo esta } \\
\text { influenciada pela vazão e a porosidade. }\end{array}$ \\
\hline $\mathrm{K}$ & $\begin{array}{l}\text { É uma propriedade advinda da lei de Darcy, que mede a } \\
\text { facilidade com que a água passa pelo solo. Quanto maior o valor } \\
\text { de K menor será a resistência, ou seja, maior a facilidade com } \\
\text { que a água ou a solução contaminante se move no solo. }\end{array}$ \\
\hline $\mathrm{Dh}$ & $\begin{array}{l}\text { É um parâmetro que propicia uma medida da difusão do } \\
\text { contaminante pelo solo. }\end{array}$ \\
\hline $\mathrm{R}$ & $\begin{array}{l}\text { Está diretamente relacionado com a capacidade de } \\
\text { adsorção/retenção do contaminante às partículas de solo. }\end{array}$ \\
\hline Kd & $\begin{array}{l}\text { Corresponde a uma das formas de avaliar-se a sorção e a } \\
\text { mobilidade dos contaminantes no solo. Quanto maior o Kd, } \\
\text { maior será a tendência do contaminante ficar adsorvido ao solo. } \\
\text { É a relação entre as concentrações adsorvidas e em solução, que } \\
\text { permite a comparação do comportamento de elementos em } \\
\text { diferentes sistemas. }\end{array}$ \\
\hline Fonte: Elaborado pelos Autores com base em Selim e Amacher [51] e Correia \\
\hline
\end{tabular}
[52].

\section{Interações chumbo-solo}

As forças das ligações entre os metais tóxicos e as partículas do solo dependem fundamentalmente do $\mathrm{pH}$, a carga e o raio iônico dos íons metálicos. As forças de ligação diminuem com o aumento do $\mathrm{pH}$, já quanto a carga, os íons com maior carga se ligam mais fortemente às partículas do solo, além de que íons de maior raio iônico são mais rapidamente sorvidos pelas partículas do solo [38].

A adsorção pode ser vista como um processo chave para se determinar o destino dos poluentes no sistema solo-água. Esta habilidade que o solo possui na retenção de solutos retarda seu transporte no perfil do solo. O comportamento de metais tóxicos nos solos, provenientes de uma carga poluidora é controlada pelas características físicas, químicas e mineralógicas de cada solo [30]. Características e propriedades como teor de argila e de matéria orgânica, capacidade de troca catiônica (CTC) e pH, entre outras, têm sido avaliadas como possíveis indicadores da capacidade de adsorção dos solutos pelo solo (Koskinen e Harper, 1990 apud [53]). Em geral, a adsorção de metais tóxicos é pequena a valores baixos de $\mathrm{pH}$, e em altos valores de $\mathrm{pH}$, os íons metálicos são completamente retidos [54].

Solos de textura argilosa, por exemplo, apresentam uma maior capacidade de reter os metais porque eles apresentam uma maior área superficial específica, e em geral maior CTC, onde os metais tóxicos podem se ligar. Essa ligação geralmente acontece por complexo de esfera interna, ou seja, é uma ligação muito forte, 
capaz de imobilizar o metal, diminuindo muito os riscos de lixiviação desses elementos, o que, a princípio, evitaria a contaminação do lençol freático e a contaminação dos solos próximos ao local [55].

Alguns estudos trazem em suas discussões que a interação, a disponibilidade e a afinidade do metal chumbo variam conforme os diferentes tipos de solos e composições minerais, porém, segundo Benedetti [56], o íon chumbo, comparado a outros metais tóxicos, possui elevada afinidade para adsorção tanto em solos com estrutura 1:1 quanto $2: 1$.

A adsorção de chumbo ocorre fundamentalmente quando os contaminantes se acumulam na superfície da argila levando à sua imobilização através dos processos de troca iônica, interações de íon dipolo ou ativação dos íons hidroxila, sendo que, a atividade adsorvente de uma caulinita que possui carga negativa líquida zero é menor comparada à montmorilonita que possui uma carga de 0,8 unidades por cada célula unitária [57].

Um solo argiloso com a presença de bentonita foi relatado por Naseem e Tahir [58] como sendo um bom adsorvente de chumbo. A adsorção apresentada foi de $20 \mathrm{mg}$ de chumbo por grama de argila, a um $\mathrm{pH}$ de 3,4 , sendo que esta poderá aumentar de 30 a 94,5\% com um acréscimo do $\mathrm{pH}$ da solução de 1,4 a 3,4, e diminuir para $40 \%$ a um pH de 5,0. Contudo, a capacidade de adsorção para as interações chumbo e bentonita foi mostrado ser de 52,6 $\mathrm{mg} \mathrm{g}^{-1}$, podendo alcançar uma adsorção maior que $96 \%$ dentro de 10 minutos de interação.

Neste mesmo sentido, alguns estudos comparam a capacidade adsorvente dos argilominerais caulinita e montmorilonita na remoção do metal chumbo, sendo que, nestes casos a adsorção máxima foi alcançada dentro de 40 minutos. Em uma mesma concentração de chumbo e temperatura, a montmorilonita mostrou maior capacidade de adsorção $(86,5 \%)$ comparada à caulinita $(20,9 \%)$, sendo que, esta porcentagem aumentou em ambos quando o solo sofreu uma ativação ácida. Além disto, foi relatado que houve uma diminuição na adsorção de chumbo com o aumento da temperatura, fato este explicado em função das interações entre o chumbo e os argilominerais serem fortemente exotérmicas [59-60].

No estudo realizado por Sällström [61], o solo argiloso com componente dominante de quartzo e estrutura cristalina composta de sílica mostrou-se eficaz na remoção do metal chumbo através da adsorção, sendo que, dentre a gama de $\mathrm{pH}$ de 4,7 e 6,5 o chumbo foi removido de $0 \%$ a $100 \%$. Estes resultados foram obtidos de forma semelhante para o solo argiloso que possuía componentes principais de alumínio e ferro e, em menor extensão de sílica e do mineral haloisita, sendo que, neste solo o chumbo teve uma adsorção de $70 \%$ a pH 4 e uma remoção completa a pH 7. Além disto, a capacidade de troca catiônica dos solos apresentou-se excepcionalmente baixa.

Das e colaboradores [62] estudaram um solo de mineração com composição natural de argila barrosa, lama, sais minerais e rochas, sendo que, as cores apresentadas pelo solo eram principalmente marrom, tijolo vermelho e castanho. A mineralogia do solo era composta por uma mistura heterogênea de argila caulinita, quartzo, cromita, goethita e hematita. A presença do contaminante chumbo não se apresentou muito significativa, ficando em penúltimo lugar no ranking dos metais tóxicos encontrados no solo, com variação de sua concentração de $0,13 \pm 0,12$ a 4,35 $\pm 0,43 \mathrm{mg} \mathrm{kg}^{-1}$, não ultrapassando os limites de segurança. $\mathrm{O}$ solo apresentou baixo teor de nutrientes $(\mathrm{N}, \mathrm{P}, \mathrm{K}$, carbono orgânico) e uma faixa de $\mathrm{pH}$ aproximadamente neutra,

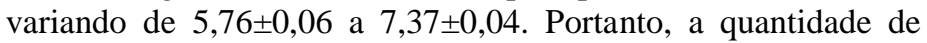
contaminante disponível está diretamente relacionada com a especiação do metal, a sua toxicidade e as fases minerais do solo.

A importância da mineralogia do solo também é descrita por Sant'Anna de Araújo [63]. O estudo demonstrou que o teor de argila e sua composição mineralógica, é a principal responsável pela adsorção de chumbo nos solos utilizados, além da capacidade de troca catiônica efetiva e o pH. Também, neste estudo foi verificado que o chumbo apresenta maior afinidade pelo grupo funcional $\mathrm{OH}$ - (hidroxila) presente na superfície da caulinita, óxidos, oxihidróxidos e hidróxidos de ferro e alumínio e menor afinidade pelos grupos funcionais de substâncias húmicas.

\section{Transporte do chumbo em diferentes tipos de solos}

\subsection{Estudo de caso I}

No estudo realizado por Irha e colaboradores [64] foram utilizados 4 tipos de solos diferentes com composições diferentes, podzoluvisol (silt and sand), podzol (sandy till), Rendzic Leptosol (till and silt) e Podzolic Gleissolo ( $t$ ill $)$. O pH do subsolo variou de 6,9 a 7,2. A composição mineral do subsolo foi caracterizada pela alta variação no conteúdo de quartzo, argila, calcita e dolomita.

A sequência de valores encontrados na diminuição do coeficiente de distribuição $(\mathrm{Kd})$ foram: $\mathrm{Pb}>\mathrm{Cr}>\mathrm{Cu}>\mathrm{Cd}$ para o solo Podzoluvisol, $\mathrm{Cr}>\mathrm{Pb}>\mathrm{Cu}>\mathrm{Cd}$ para o solo Podzol, $\mathrm{Pb}>\mathrm{Cu}>$ $\mathrm{Cr}>\mathrm{Cd}$ para Podzolic Gleissolo e $\mathrm{Pb}>\mathrm{Cu}>\mathrm{Cd}>\mathrm{Cr}$ para Rendzic Leptosol. Os quatro subsolos estudados têm uma maior afinidade para o Chumbo comparado com os outros metais e, como esperado, os valores de $\mathrm{Kd}$ mais baixos de $\mathrm{Cd}, \mathrm{Pb}$ e $\mathrm{Cu}$ foram obtidas para Podzol, que é composto por areia.

Os maiores valores de $\mathrm{Kd}$ para os metais foram obtidos em subsolos com alto teor de carbonatos e/ou minerais de argila e compostos $\mathrm{Mn} / \mathrm{Fe}$. Os resultados indicaram um papel significativo 
tanto da calcita quanto da dolomita na interação de metais tóxicos com a matéria do subsolo, sendo a associação entre os valores $\mathrm{Kd}$ e chumbo e o conteúdo dolomita muito forte.

Solos com valores altos de Kd terão maior capacidade de retenção, porém, quando esta capacidade sortiva for excedida, o metal pode passar livremente para o subsolo, sendo que, para que este não chegue às águas subterrâneas, o subsolo também deve apresentar um Kd elevado. Assim, os valores elevados de Kd para o chumbo indicaram uma ótima retenção deste metal em todos os tipos de solo. Os valores maiores de Kd no Horizonte C comparado ao Horizonte A indicaram que o chumbo lixiviado a partir da camada superior do solo será acumulado facilmente no subsolo.

Portanto, os resultados obtidos neste trabalho indicaram a importância das características do subsolo na avaliação da acumulação de metais tóxicos no solo e o potencial de contaminação das águas subterrâneas.

\subsection{Estudo de caso II}

No mesmo sentido do estudo de caso I, que relacionou o Kd com a capacidade de retenção de metais, Arabzai e Honma [65] analisaram a adsorção e transporte dos íons metálicos $\mathrm{Pb}^{2+}, \mathrm{Cu}^{2+} \mathrm{e}$ $\mathrm{Cd}^{2+}$ em quatro tipos de solos diferentes (lama, argila bentonita, argila caulinita e areia), e concluíram que o valor de $\mathrm{Kd}$ diminui rapidamente na ordem lama> bentonita> caulinita> areia. Desta forma, a adsorção/retenção do $\mathrm{Pb}^{2+}$ para solos seguiu esta mesma ordem, lama> bentonita> caulinita> areia. Portanto, quanto maior os valores de $\mathrm{Kd}$ maior será a retenção do metal chumbo nos solos.

\subsection{Estudo de caso III}

Fonseca e colaboradores [66] estudaram a retenção de $\mathrm{Cr}(\mathrm{VI})$ e $\mathrm{Pb}$ (II) em um solo areno- argiloso, localizado em Póvoa de Varzim, Portugal. As amostras de solo foram coletadas na profundidade de 0 a $50 \mathrm{~cm}$. O solo foi homogeneizado, seco ao ar e passado na peneira de $2 \mathrm{~mm}$. Ele foi classificado como uma areia argilosa ácida, com alto teor de matéria orgânica, baixa CTC. Além disso, foi verificada a ausência natural do metal chumbo no solo. Os argilominerais predominantes na amostra são a caulinita, seguida da ilita, esmectita e material interestratificado.

Foram realizados ensaios de coluna e geradas as curvas de chegada (breakthrough). Para o ensaio com a solução de chumbo a um pH de 5, a curva indicou que não houve saturação na coluna. Por outro lado, a um $\mathrm{pH}$ de 2, o chumbo apresentou maior mobilidade. Foi observado que o fator de retardação obtido para a solução de $\mathrm{pH}$ mais alto foi cerca de 19 vezes maior que o fator de retardação (R), obtido com $\mathrm{pH}$ de 2, contendo a mesma concentração de chumbo. Esse comportamento é devido ao fato de que altos valores de $\mathrm{pH}$ ao longo do experimento promovem a precipitação do metal. Além disso, observou-se que houve maior retenção na parte inferior da coluna, onde há a alimentação do soluto, para os ensaios com $\mathrm{pH}$ de 5 , houve rapidamente a imobilização do contaminante. Os testes confirmaram que a retenção de chumbo no solo aumenta com o aumento do $\mathrm{pH}$ devido ao fenômeno de precipitação. Dessa forma, os autores concluíram que houve grande mobilidade de chumbo em meios ácidos, podendo comprometer a qualidade das águas subterrâneas nesses locais.

\subsection{Estudo de caso IV}

Fonseca e colaboradores [67], realizaram um estudo sobre a mobilidade de $\mathrm{Cr}, \mathrm{Pb}, \mathrm{Cd}, \mathrm{Cu}$ e $\mathrm{Zn}$ em um solo areno-argiloso, cuja caracterização está apresentada em Fonseca e colaboradores [66], e concluiu que esse tipo de solo possui uma elevada afinidade para todos os metais testados, dada na seguinte ordem: $\mathrm{Cr}>\mathrm{Pb}>\mathrm{Cd}>\mathrm{Cu}>\mathrm{Zn}$. Para as capacidades máximas de sorção, as tendências foram: $\mathrm{Cu} \approx \mathrm{Zn}>\mathrm{Cd}>\mathrm{Pb}>\mathrm{Cr}$. Os resultados dos testes de fluxo mostraram que os fatores de retardamento apresentaram a seguinte tendência: $\mathrm{Zn}>\mathrm{Cd}>\mathrm{Pb}>\mathrm{Cu}>\mathrm{Cr}$. Geralmente, em situações competitivas, os metais tóxicos são menos adsorvidos pelo solo, devido à competição por sítios de sorção. A existência de competição entre os metais tóxicos nem sempre reduz a sua retenção no solo, pois depende também da concentração, pH e tipos de metais envolvidos. Outros processos, além de adsorção também podem ocorrer, de forma a influenciar a seleção de técnicas de descontaminação.

\subsection{Estudo de caso $V$}

$\mathrm{O}$ transporte de soluções contaminantes de $\mathrm{Pb}$ e $\mathrm{Cu}$ foi avaliado por Shahmohammadi-kalalagh e colaboradores [68] em uma coluna de solo argiloso homogêneo saturado, composto fundamentalmente pelo argilomineral caulina com $\mathrm{pH}$ ajustado para 4,5. O fator de retardamento (R) foi estimado pelos métodos da curva de chegada (breakthrough) e da função de erro (Erfc). $\mathrm{O}$ parâmetro $\mathrm{R}$ revelou tendência maior para o $\mathrm{Pb}$ comparado ao $\mathrm{Cu}$ $(\mathrm{Pb}>\mathrm{Cu})$, indicando que a mobilidade dos metais tóxicos na coluna de solo é maior para o $\mathrm{Cu}$ em relação ao $\mathrm{Pb}(\mathrm{Cu}>\mathrm{Pb})$. Já comparado à profundidade da coluna, este fator aumentou com a distância para ambos os metais. Portanto, a taxa de transporte de metal em solo argiloso segue a ordem $\mathrm{Cu}>\mathrm{Pb}$.

\subsection{Estudo de caso VI}

Elbana [69] analisou o transporte dos metais $\mathrm{Pb}, \mathrm{Cu}$ e $\mathrm{Cd}$ em solos alcalinos e ácidos, e concluiu que o Chumbo é fortemente adsorvível (99,5\%), com recuperação de menos do que $0,5 \%$ da mobilidade de Chumbo na solução efluente, porém, quando aplicado na areia, exibiu elevada mobilidade. Além disto, uma quantidade de 85 a $93 \%$ de Chumbo foi retida já na superfície de 
$2 \mathrm{~cm}$ da coluna de solo. Também, foi observado que o Chumbo associou-se principalmente com as frações de carbonato e óxidos.

\subsection{Estudo de caso VII}

Soares [70] analisou o coeficiente de distribuição Kd de metais tóxicos em solos do Estado de São Paulo. Os solos foram selecionados buscando um conjunto heterogêneo quanto aos atributos químicos, físicos e mineralógicos. Os locais de amostragem se deram nos maiores centros urbanos do Estado, pela maior probabilidade de os solos estarem sujeitos à contaminação, devido à aterros sanitários, disposição de resíduos sólidos, águas residuárias urbanas e industriais. Foram coletadas 30 amostras de solo de diferentes regiões e analisados com 7 metais tóxicos $(\mathrm{Pb}$, $\mathrm{Cu}, \mathrm{Cd}, \mathrm{Zn}, \mathrm{Ni}, \mathrm{Cr}$ e $\mathrm{Co}$ ).

$\mathrm{O}$ autor concluiu que a afinidade em função dos valores de $\mathrm{Kd}$ se deu na seguinte ordem: $\mathrm{Pb}>\mathrm{Cu}>\mathrm{Cd}>\mathrm{Zn} \approx \mathrm{Ni} \approx \mathrm{Cr}>\mathrm{Co}$. Exceto o $\mathrm{Cu}$, os metais de transição apresentaram valores médios de $\mathrm{Kd}$ semelhantes, sendo que o $\mathrm{pH}$ foi o fator que mais afetou os valores de $\mathrm{Kd}$. O chumbo e o cobre, que são elementos menos móveis, tiveram os valores de $\mathrm{Kd}$ influenciados pela porção de argila juntamente com o $\mathrm{pH}$. Os valores de $\mathrm{Kd}$ encontrados foram similares aos utilizados pela Cetesb, exceto os de Ni e Cr.

\section{Conclusões}

Diante da séria contaminação de solos por metais tóxicos em muitas áreas do mundo e em função, principalmente, da toxicidade, persistência no solo e efeito bioacumulativo, é essencial compreender a sua mobilidade e interação em diferentes tipos de solos. Nesse contexto, a revisão bibliográfica realizada permitiu as seguintes conclusões:

i. O solo é um importante reservatório para contaminantes, sendo que a presença de matéria orgânica e a composição e propriedades mineralógicas, como tipo de estrutura, capacidade de troca catiônica (CTC) e área superficial são essenciais condicionantes para tal interação. Além de que, assegurar esta condição é fundamental para minimizar os riscos de contaminação das águas subterrâneas;

ii. Os argilominerais de estrutura tipo 2:1 apresentam maior área de superfície total do que os do tipo 1:1. Da mesma forma, os minerais 2:1 (expansíveis) possuem uma maior CTC quando comparado aos minerais 1:1 (não expansíveis), o que proporciona maior propensão para a imobilização e retenção de íons metálicos. $\mathrm{O}$ íon chumbo possui elevada afinidade para adsorção tanto em solos com estrutura 1:1 quanto $2: 1$; iii. Solos granulares facilitam a mobilidade do contaminante no solo. Além disto, solos com valores altos de coeficiente de distribuição $(\mathrm{Kd})$ terão maior capacidade de retenção, porém, quando esta capacidade sortiva for excedida, o metal pode passar livremente para o subsolo, sendo que, para que este não chegue às águas subterrâneas, o subsolo também deve apresentar um Kd elevado;

iv. Quando comparado com demais metais tóxicos, o chumbo apresenta grande afinidade em função dos valores de $\mathrm{Kd}$ e fator de retardamento $(\mathrm{R})$, indicando menor mobilidade no perfil do solo, ou seja, maior retenção;

v. De forma geral, a retenção de chumbo no solo aumenta com o aumento do $\mathrm{pH}$ devido ao fenômeno de precipitação, havendo grande mobilidade de chumbo em meios ácidos, o que pode comprometer a qualidade das águas subterrâneas nesses locais;

vi. Portanto, a estabilidade, forma de existência e mobilidade do chumbo no solo é influenciada diretamente pelo $\mathrm{pH}$, sendo que, dependendo da faixa de $\mathrm{pH}$ são encontradas espécies variadas, podendo sofrer modificações, formar compostos menos solúveis e tornar-se menos disponível.

\section{Agradecimentos}

Ao grupo de pesquisa em Geotecnia Ambiental da Universidade de Passo Fundo e a CAPES pela concessão de bolsas de estudo.

\section{MECHANISMS OF INTERACTION AND TRANSPORTATION OF LEAD METAL IN DIFFERENT SOIL COMPOSITIONS}

ABSTRACT: Lead, due mainly to its high toxicity and harmfulness to human health and natural ecosystems, is a toxic metal harmful in any concentration to living organisms. In view of this, this work aimed to verify the behavior, interaction, mobility and transport of the lead metal in the most diverse types and compositions of soils. In order to achieve this objective, a characterization of the lead metal was performed, discussing its main physicochemical properties, a study on the geochemical properties of soils, and the identification of the transport parameters which directly influence the interaction and transport of the contaminant in the soil. The results indicated that the adsorptive capacity is the most evidenced process in the interactions between the soil and the lead. In relation to transport, this is influenced fundamentally by factors such as the fluid flow in which the contaminants are dissolved, besides the 
characteristics of the contaminant, the soil and the environmental conditions. Therefore, it is concluded that the specific physicalchemical properties of the lead metal, together with the mineralogical characteristics and compositions of each soil with which this contaminant interacts, are parameters that guide the behavior of the lead metal in the soil, as to its availability, mobility and the possibility of removal.

Keywords: Soil pollution. Toxic metals. Soil-contaminant interaction. Mobility parameters.

\section{Referências}

1. CASTELO-GRANDE, T.; BARBOSA, D. "Soil decontamination by supercritical extraction". Electronic Journal of Environmental, Agricultural and Food Chemistry, v. 2, n. 2, 2003.

2. CHEN, M.; XU, P.; ZENG, G.; YANG, C.; HUANG, D.; ZHANG, J. Bioremediation of soils contaminated with polycyclic aromatic hydrocarbons, petroleum, pesticides, chlorophenols and heavymetals by composting: Applications, microbes and future research needs. Biotechnology Advances, v. 33, n. 6, p. 745-755, 2015.

3. ALLOWAY, B. J. Heavy metals in soils. 2 ed., London: Blackie Academic \& Professional, 1995.

4. PASCALICCHIO, Á. A. E. Contaminação por metais pesados. São Paulo: Annablume, 132 p., 2002.

5. TAVARES, S. R. de L. Remediação de solos e águas contaminadas por metais pesados: Conceitos básicos e fundamentos. Rio de Janeiro, 1 ed., 147 p., 2013

6. MUÑOZ, S. I. S. Impacto ambiental na área do aterro sanitário e incinerador de resíduos sólidos de Ribeirão Preto, SP: avaliação dos níveis de metais pesados. 2002. 158 p. Tese (Doutorado em Enfermagem em Saúde Pública) - Escola de Enfermagem de Ribeirão Preto/Universidade de São Paulo, Ribeirão Preto, 2002.

7. BAPTISTA, A. Avaliação do potencial de recuperação de metais de catalisadores equilibrados através da técnica de remediação eletrocinética. 2005. 151 p. Dissertação (Mestrado em Engenharia de Materiais e Processos) - Universidade Federal do Paraná, Curitiba, 2005.

8. CARVALHO, J. C. B. de; COSTA ORSINE, J. V. Contaminação do meio ambiente por fontes diversas e os agravos à saúde da população. Enciclopédia Biosfera - Centro Científico Conhecer, v.7, n.13, pg. 1107 $-1118,2011$.

9. ABRAHAM, J.; DOWLING, K.; FLORENTINE, S. Assessment of potentially toxic metal contamination in the soils of a legacy mine site in Central Victoria, Australia. Chemosphere, v. 192, p. 122-132, 2018.

10. LEE, P.-K; JO, H. Y.; CHI, S.-J.; PARK, S.-W. Metal contamination and solid phase partitioning of metals in the stream and bottom sediments in a reservoir receiving mine drainage. Applied Geochemistry, V. 28, p. 80-90, 2013.

11. NANNONI F.; PROTANO G. Chemical and biological methods to evaluate the availability of heavy metals in soils of the Siena urban area
(Italy). Science of the Total Environment, 568, 1-10, 2016.

12. PONTONI L.; HULLEBUSCH E. D.; FABBRICINO M.; ESPOSITO G.; PIROZZI F. Assessment of trace heavy metals dynamics during the interaction of aqueous solutions with the artificial OECD soil: Evaluation of the effect of soil organic matter content and colloidal mobilization. Chemosphere, 163, 382-391, 2016.

13. JESUS, L. D. F.; MOREIRA, M. F. R.; AZEVEDO, S. V.; BORGES, R. M.; GOMES, R. A. A.; BERGAMINI, F. P. B.; TEIXEIRA, L. R. Avaliação dos níveis de chumbo e mercúrio em população exposta ambientalmente na Região Centro-oeste do Brasil. Caderno de Saúde Pública, v. 34(2), p. 1-13, 2018

14. CHRASTNÝ, V.; SILLEROVA, H.; VÍTOKA, M.; FRANCOVA, A.; JEHLICKA, J.; KOCOURKOVA, J.; ASPHOLM, P. E.; NILSSON, L. O.; BERGLEN, T. F.; JENSEN, H. K. B.; KOMAREK, M. Unleaded gasoline as a significant source of $\mathrm{Pb}$ emissions in the Subarctic. Chemosphere, v. 193, p. 230-236, 2018.

15. KLOS, A.; ZIEMBIK, Z.; RAJFUR, M.; DOŁHAŃCZUK-ŚRÓDKA, A.; BOCHENEK, Z.; BJERKE, J. W.; TØMMERVIK, H.; ZAGAJEWESKI, B.; ZIÓŁKOWSKI, D.; JERZ, D.; ZIELIŃSKA, M.; KREMS, P.; GODYN, P.; MARCINIAK, M.; ŚWISŁOWSKI, P. Using moss and lichens in biomonitoring of heavy-metal contamination of forest areas in southern and north-eastern Poland. Science of the Total Environment, v. 627, p. 438-449, 2018.

16. RIBEIRO, M. A. do C. Contaminação do solo por metais pesados. 2013. 249 p. Dissertação (Mestrado em Engenharia do Ambiente) - Faculdade de Engenharia, Universidade Lusófona de Humanidades e Tecnologias, Lisboa, 2013.

17. YEUNG, A. T. Contaminant Extractability by Electrokinetics. Environmental Engineering Science, v. 23 n. 1, p. 202-224, 2006.

18. IPCS, International Programme on Chemical Safety. Environmental Health Criteria 165 for Inorganic Lead. World Health Organization, Geneva,1995.

19. TAKAHASHI, T; DAHLGREN, R. A.; THENG, B. K. G.; WHITTON, J. S.; SOMA, M. Potassium-selective, halloysite-rich soils formed in volcanic materials from Northern California, Soil Science Society of America Journal, v. 65, p. 516-526, 2001.

20. GUSTAFSSON, J. P.; JACKS, G.; SIMONSSON, M.; NILSSON, I. Soil and water chemistry, Royal Institute of Technology (KTH). Department of Water Resources Engineering, Stockholm, 2007.

21. DEMUELENAERE, R. G. A. Caracterização de Propriedades de Transporte de metais Pesados em Solos Residuais do Rio de Janeiro. 2004. 120 f. Dissertação (Mestrado em Engenharia Civil), PUC-Rio, Rio de Janeiro, 2004.

22. REDDY, K. R.; ADAMS, J. A. Sustainable Remediation of Contaminated Sites. Momentum Press, LLC, New York, 268 p., 2015.

23. FERNANDES, J. D.; DANTAS, E. R. B.; BARBOSA, J. N.; BARBOSA, E. A. Estudo de impactos ambientais em solos: o caso da reciclagem de baterias automotivas usadas, tipo chumbo-ácido. Revista Brasileira de Gestão e Desenvolvimento Regional - GDR, Taubaté/SP, v. 7, n. 1, p. 231-255, 2011.

24. MACHADO, I. P. Avaliação Ambiental do Processo de Reciclagem do Chumbo. 2002. 116 p. Dissertação (Mestrado em Engenharia 
Mecânica) - Universidade Estadual de Campinas/Faculdade de Engenharia Mecânica, Campinas, 2002.

25. MULliGAN, C. N.; YOUNG, R. N.; GIBBS, B. F. An evaluation of technologies for the heavy metal remediation of dredged sediments. Journal of Hazardous Materials, v. 85, p. 145-163, 2001.

26. TRAN, H. H.; RODDICK, F. A.; O'DONNELL, J. A. Comparison of chromatography and desiccant silica gels for the adsorption of metal ions. I. Adsorption and kinetics. Water Research, v. 33, n. 13, p. 2992 3000, 1999.

27. KREUSCH, M. A. Avaliação com propostas de melhoria do processo industrial de reciclagem do chumbo e indicação de aplicabilidade para a escória gerada. 2005. 129 p. Dissertação (Mestrado em Engenharia Química) - Universidade Federal do Paraná, Curitiba, 2005.

28. HSDB, Hazardous Substances Data Bank. Lead. National Library of Medicine. 2016. Disponível em: https://toxnet.nlm.nih.gov/cgibin/sis/search2/f?./temp/ I4bLq2:2. Acesso em 19/01/2019.

29. ICZ - Instituto de Metais Não Ferrosos. Chumbo, Disponível em: http://www.icz.org.br/chumbo.php. Acesso em: 19/01/2019.

30. KABATA-PENDIAS, A.; PENDIAS, H. Trace elements in soils and plants. CRC Press, n.3, p. 413, 2001.

31. GARBA, S. T.; ABUBAKAR, M. A. Source and Distribution of The Heavy Metals: $\mathrm{Pb}, \mathrm{Cd}, \mathrm{Cu}, \mathrm{Zn}, \mathrm{Fe}, \mathrm{Cr}$, and $\mathrm{Mn}$ in Soils of Bauchi Metropolis, Nigeria. American Journal of Engineering Research, v. 7(2), p. 13-23, 2018.

32. POURBAIX, M. Atlas of electrochemical equilibria in aqueous solutions. 2.ed., Texas, USA: National Association of Corrosion Engineers (NACE International \& Cebelcor), 644 p., 1974.

33. BRASIL. Conselho Nacional do Meio Ambiente (CONAMA), Resolução n ${ }^{\circ} 420$ de 28 de dezembro de 2009. Diário Oficial da União, Poder Executivo, Brasília, DF, 30 de dezembro de 2009, p.81-84.

34. BRAGA, B. et al. Introdução à Engenharia Ambiental. 2 ed., São Paulo: Prentice Hall, 2005.

35. DERISIO, J. C. Introdução ao Controle de Poluição Ambiental. 4 ed. São Paulo: Oficina de Textos, 2012.

36. LEWIS, B. G. Environmental and Ecological Chemistry, Encyclopedia of life support systems. Soil Chemistry, v. 2, p. 78-114, 2009.

37. ERIKSSON, J.; NILSSON, I.; SIMONSSON M. Wiklanders Marklära. 1 ed. Lund: Studentlitteratur, 337 p., 2005.

38. DUBE, A.; ZBYTNIEWSKI, R.; KOWALKOWSKI, T.; CUKROWSKA, E.; BUSZEWSKI, B. Adsorption and Migration of Heavy Metals in Soil. Polish Journal of Environmental Studies, v. 10, n. 1 , p. 1-10, 2001

39. KORTE, N. E.; SKOPP J.; FULLER, W. H.; NIEBLA, E. E.; ALESII, B. A. Trace elements movements in soils. Influence of soil physical and chemical properties. Soil Science, v. 122, n. 6, p. 350-359, 1976.

40. YOUNG, A. Tropical soils and soil survey. Cambridge University Press, Cambridge, U.K, 1976.

41. CHANG, R. Chemistry. 8 ed., New York: McGraw-Hill College, 2005.
42. BEAR, J. Dynamics of fluids in porous media. New York, Dover Publications, 764p., 1972

43. FREEZE, R. A.; CHERRY, J. A. Groundwater. Prentice-Hall, Englewood Cliffs, NJ. 604p., 1979.

44. KNOP, A. Estudo do comportamento de liners atacados por ácido sulfúrico. 2007. 256p. Tese (Doutorado em Engenharia Civil, Geotecnia e Meio Ambiente), Universidade Federal do Rio Grande do Sul - Porto Alegre, 2007.

45. MONCADA, M. P. H. Estudo em Laboratório de Características de Colapso e Transporte de Solutos Associados à Infiltração de Licor Cáustico em um Solo Laterítico. 2004. 190p. Dissertação (Mestrado em Engenharia), Pontifícia Universidade Católica do Rio de Janeiro/PUCRJ - Rio de Janeiro, 2004.

46. COELHO, H. M. G.; SIMÕES, G. F.; LANGE, L. C.; FERREIRA, C. F. A. Transporte de contaminantes em meios porosos saturados. 1987. Dissertação (Mestrado em Engenharia Civil) - Departamento de Engenharia Civil, PUC-RIO, Rio de Janeiro, 1987.

47. SISSOM, L. E.; PITTS, D. R. Fenômenos de Transporte. Rio de Janeiro/RJ: Editora Guanabara, 1988

48. ALSHAWABKEH, A. N.; ACAR, Y. B. Principles of Species Transport in saturated Soils under a Electric Field. Waste Disposal by Landfill - GREEN' 93, Rotterdam, p. 225-232, 1993.

49. LAGREGA, M. D.; BUCKINGHAM, P. L; EVANS, J. C. Stabilisation and solidification. Hazardous Waste Management, McGraw-Hill, p. 641-704, 1994.

50. CHARDON, W.; SCHOUMANS, O. Solubilization of phosphorus: concepts and process description of chemical mechanisms. Meeting of COST 832, WG2, Cordoba, 1999.

51. SELIM, H. M.; AMACHER, M. C. Reactivity and transport of heavy metals in soils. CRC Press, 1996.

52. CORREIA, F. B.; LANGENBACH, T.; CAMPOS, T. M. Avaliação do transporte de atrazina em solos sob diferentes condições de manejo agrícola. Revista Brasileira de Ciência do Solo, v. 34, p. 525-534, 2010.

53. OLIVEIRA, L. F.C.; LEMKE-DE-CASTRO, M. L.; RODRIGUES, C.; BORGES, J. D. Isotermas de sorção de metais pesados em solos do cerrado de Goiás. Revista Brasileira de Engenharia Agrícola e Ambiental, v. 14, n. 7, p. 776-782, 2010

54. BRADL, H. B. Adsorption of heavy metal ions on soils and soils constituents. Journal of Colloid and Interface Science, v. 217, p. 1-18, 2004.

55. LAUERMANN, A. Caracterização química dos efluentes gerados pelo aterro controlado de santa maria e retenção de chumbo e zinco por um argissolo da depressão central do rio grande do sul. 2007. 72 f. Dissertação (Mestrado em Ciência do Solo), Universidade Federal de Santa Maria, Santa Maria, 2007.

56. BENEDETTI, M. F.; MILNE，C. J., KINNIBURGH， D. G.; VAN RIEMSDIJK, W. H.; KOOPAL, L. K. Metal ion binding to humic substances: application of the non-ideal competitive adsorption model. Environmental Science and Technology, v. 29, n. 2, p. 446-457, 1995.

57. BHATTACHARYYA, K. G.; GUPTA, S. S. Adsorption of a few heavy metals on natural and modified kaolinite and montmorillonite: A 
review. Advances in Colloid And Interface Science, v. 140, n. 2, p.114131,2008

58. NASEEM, R.; TAHIR, S. S. Removal of Pb(II) from aqueous/acidic solutions by using bentonite as an adsorbent. Water Research, v. 35, n. 16, p. 3982-3986, 2001.

59. GUPTA, S. S.; BHATTACHARYYA, K. G. Interaction of metal ions with clays: I. A case study with $\mathrm{Pb}(\mathrm{II})$. Applied Clay Science, v. 30, n. 3-4, p.199-208, 2005.

60. BHATTACHARYYA, K. G.; GUPTA, S. S. Pb (II) uptake by kaolinite and montmorillonite in aqueous medium: Influence of acid activation of the clays. Colloids and Surfaces A: Physicochemical and Engineering Aspects, v. 277, n. 1-3, p.191-200, 2006.

61. SÄLLSTRÖM, M. Physico-chemical characteristics of some soils from Mali and their potential in heavy metal removal. 2008. 58 p. Thesis (Master's in Soil Science) - Swedish University of Agricultural Sciences, Uppsala, 2008.

62. DAS, S.; RAM, S. S.; SAHU, H. K.; RAO, D. S.; CHAKRABORTY, A.; SUDARSHAN, M.; THATOI, H. N. A study on soil physicochemical, microbial and metal content in Sukinda chromite mine of Odisha, India. Environ. Earth Sci., v. 69, n. 8, p. 2487-2497, 2012.

63. SANT'ANNA DE ARAÚJO, W. Influência das propriedades físicas e químicas de solos intemperizados na adsorção de chumbo,cobre e zinco. Floresta e Ambiente, v. 7, n.1, p.167-180, 2000.

64. IRHA, N.; STEINNES, E.; KIRSOR, U.; PETERSELL, V. Transport of $\mathrm{Cd}, \mathrm{Pb}, \mathrm{Cu}$ and $\mathrm{Cr}$ in different soils. International Conference on Environmental Management, Engineering, Planning and Economics, Skiathos, p. 277-281, 2007.

65. ARABZAI, A.; HONMA, S. Adsorption and Transport of Heavy Metal Ions in Saturated Soils. Proceedings of the School of Engineering of Tokai University, v. 39, p. 27-32, 2014.

66. FONSECA, B.; MAIO, H., QUINTELAS, C.; TEIXEIRA, A.; TAVARES, T. Retention of $\mathrm{Cr}(\mathrm{VI})$ and $\mathrm{Pb}$ (II) on a loamy sand soil Kinetics, equilibria and breakthrough. Chemical Engineering Journal, v. 152 , p. $212-219,2009$.

67. FONSECA, B.; FIGUEIREDO, H.; RODRIGUES, J.; QUEIROZ, A.; TAVARES, T. Mobility of $\mathrm{Cr}, \mathrm{Pb}, \mathrm{Cd}, \mathrm{Cu}$ and $\mathrm{Zn}$ in a loamy sand soil: A comparative study. Geoderma, v. 164, p. 232-237, 2011.

68. SHAHMOHAMMADI-KALALAGH, S.; NAZEMI, A.; BABAZADEH, H.; MANSHOURI, M. Estimating lead and copper transport parameters from unsaturated clay soil column. International Research Journal of Applied and Basic Sciences. v. 3, n. 4, p. 675-681, 2012.

69. ELBANA, T. A. Transport and adsorption-desorption of heavy metals in different soils. 2013. 264 p. Dissertation (Doctor of Philosophy), Faculty of the Louisiana State University and Agricultural and Mechanical College, 2013.

70. SOARES, M. R. Coeficiente de distribuição Kd de metais pesados em solos do Estado de São Paulo. 2004. 214 f. Tese (Doutorado em Agronomia), Escola Superior de Agricultura Luiz de Queiroz, Universidade de São Paulo, Piracicaba, 2004. 